\title{
CONGENITAL ANOMALIES OF THE HEART IN ELEMENTARY SCHOOL CHILDREN
}

\author{
BY
}

\author{
C. BRUCE PERRY, M.D., M.R.C.P.*
}

(From the University Centre of Cardiac Research, General Hospital, Bristol.)

During the examination of a number of elementary school children referred by the school medical officer for an opinion on their cardiac condition, it was found that when those cases with no abnormal cardiac signs other than functional or hæmic bruits had been eliminated two broad groups remained. First, there were those cases presenting evidence of an acquired heart lesion, mostly rheumatic, with a few in which the cardiac abnormality followed an attack of diphtheria and one or two in which the condition was associated with renal inefficiency. The other group consisted of cases presenting various constant physical signs, strongly suggestive of a cardiac lesion, but of a congenital rather than an acquired type. An attempt has been made, by means of clinical, radiographic, and electrocardiographic investigations, to see whether these cases possess any characteristic features, and if these methods would help in any way to distinguish them from cases of acquired heart disease.

\section{Clinical investigation.}

Classification.--Symptoms definitely attributable to the cardiac defect were unusual in these cases, so that no classification based on them was practicable. Neither did any well marked distinguishing features emerge from the radiographic and electrocardiographic examinations. Thus, although it was realized that physical signs provide very insecure evidence on which to base a diagnosis of the precise anatomical defect in congenital abnormalities of the heart, it seemed the best basis, in fact almost the only basis, on which to divide up these cases. It has been found possible to place every case in one of six groups each with its characteristic and peculiar physical signs. Further, these signs have remained constant in character in those cases which have been re-examined at intervals over periods as long as three years. This, therefore, is the basis on which these cases have been studied.

Group 1.-This is composed of those cases in whom the common physical sign is a systolic murmur, varying in intensity, but maximal at the inner end of the $3 \mathrm{rd}$ and $4 \mathrm{th}$ left intercostal spaces. In some cases the murmur is audible

*Working with a Colston Research Fellowship. 
all over the præcordia but is never heard in the back. There may be also a central systolic thrill which is sometimes accentuated when the patient is examined in the crawling position, as described by Vaquez ${ }^{1}$. It seems probable that the underlying anatomical defect in these cases is a patency of the interventricular septum.

Group 2.-The signs characterizing the cases forming this group differ from the preceding only in that the murmur is conducted through to the left side of the back. These are the classical findings in patency of the interventricular septum or 'maladie de Roger.' Apparently the defect in this group differs from that in Group 1 either in the situation or size of the opening in the interventricular septum, with the result that the bruit is conducted through to the back as described.

Group 3.-The feature peculiar to this group is a systolic murmur, usually associated with a thrill, maximal at the pulmonary area, but heard also above and to the left of this and in the left back, and in many cases all over the præcordia. Most of these cases also exhibit an accentuation of the second sound at the pulmonary area. These signs, with the exception of the accentuation of the pulmonary second sound, correspond closely with those usually found in that combination of defects known as the 'tetralogy of Fallot' (i.e., pulmonary stenosis with dextro-position of the aorta and patency of the interventricular septum). However, most observers have recorded a diminution rather than an accentuation of the pulmonary second sound in this condition.

Group 4.-The physical signs of the cases forming this group differ from those found in Group 3 in that the murmur is not audible in the back, although otherwise substantially the same. Again but for the accentuation of the pulmonary second sound these signs agree closely with those usually regarded as indicative of a pulmonary stenosis.

GRovP 5.-The sign presented by the children in this group is a loud general systolic murmur, maximal at the pulmonary area, where it becomes continuous with a lower pitched diastolic murmur producing a continuous ' machinery' or 'humming top' hum. The systolic part of the bruit is audible in the left back and the pulmonary second sound is accentuated. None of these cases showed 'Gerhardt's dullness.' These signs are fairly typical of a patent ductus arteriosus.

Group 6. The cases in this group present a soft general systolic murmur which becomes much more marked at the aortic area and is conducted up into the neck along the carotids, and into both sides of the back. In most of the cases, also, it was audible over the axillary artery. The apex beat in these children is rather shock-like on palpation and the first sound at the apex is accentuated. This combination of signs is strongly suggestive of a sub-aortic stenosis.

The incidence of symptoms and other clinical features of these six groups is shown in Table 1.

Discussion.- - High colour noted in a child is obviously a very vague and indefinite symptom. The only other symptoms definitely observed were 
cyanosis and clubbing of the fingers. Cyanosis and dyspnœa on exertion must depend largely on the history obtained from the mother.

The 'attacks,' called by the parent's ' heart attacks,' are puzzling. The child is said to go pale, be dazed for a time and recover by a fit of crying. None were observed but they are rather suggestive of petit mal, and one child in the series was definitely epileptic. As is seen in Table 1, definite, well marked symptoms were rare, but were commonest in Group 3, while Group 6 is noteworthy for the complete absence of all symptoms.

Disability resulting from the cardiac condition has been estimated in terms of school life. Games and drill were prohibited in the presence of cyanosis, cardiac enlargement obvious clinically, or a definite history of easily provoked

TABLE 1.

The incidence of Symptoms and disability, given in Percentages.

\begin{tabular}{|c|c|c|c|c|c|c|c|c|c|c|c|c|c|}
\hline \multirow[b]{2}{*}{ 苞 } & \multirow[b]{2}{*}{ 峁 } & \multicolumn{2}{|c|}{$\operatorname{Sex}$} & \multicolumn{7}{|c|}{ Symptoms } & \multicolumn{3}{|c|}{ Disability } \\
\hline & & $\stackrel{n}{\stackrel{0}{c}}$ & $\stackrel{\infty}{E}$ & $\frac{50}{30}$ & 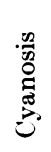 & 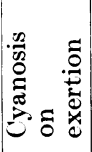 & 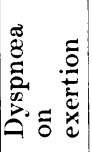 & 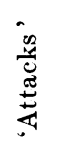 & 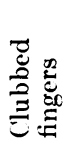 & 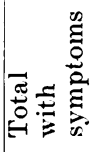 & 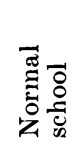 & 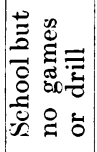 & $\begin{array}{l}\overrightarrow{0} \\
0 \\
0 \\
0 \\
0 \\
2\end{array}$ \\
\hline 1 & 37 & $64 \cdot 8$ & $35 \cdot 1$ & $5 \cdot 4$ & $2 \cdot 7$ & $2 \cdot 7$ & $2 \cdot 7$ & $8 \cdot 1$ & 一 & $13 \cdot 5$ & $97 \cdot 3$ & $2 \cdot 7$ & 一 \\
\hline 2 & 5 & $100 \cdot 0$ & 一 & $20 \cdot 0$ & - & $20 \cdot 0$ & 一 & 一 & 一 & $20 \cdot 0$ & $100 \cdot 0$ & 一 & 一 \\
\hline 3 & 39 & $53 \cdot 8$ & $46 \cdot 1$ & $28 \cdot 2$ & $7 \cdot 6$ & $10 \cdot 2$ & $10 \cdot 2$ & $5 \cdot 1$ & $5 \cdot 1$ & $49 \cdot 2$ & $87 \cdot 1$ & $10 \cdot 2$ & $2 \cdot 5$ \\
\hline 4 & 26 & $38 \cdot 4$ & $61 \cdot 5$ & $23 \cdot 0$ & 一 & $7 \cdot 6$ & $11 \cdot 5$ & - & - & $38 \cdot 4$ & $96 \cdot I$ & $3 \cdot 8$ & - \\
\hline 5 & 7 & $42 \cdot 8$ & $57 \cdot 1$ & $42 \cdot 8$ & 一 & 一 & $14 \cdot 2$ & 一 & 一 & $57 \cdot 2$ & $71 \cdot 4$ & $28 \cdot 5$ & - \\
\hline \multirow[t]{2}{*}{6} & 5 & $60 \cdot 0$ & $40 \cdot 0$ & 一 & 一 & - & 一 & - & - & 一 & $100 \cdot 0$ & - & - \\
\hline & 119 & $55 \cdot 4$ & $44 \cdot 5$ & $19 \cdot 3$ & $3 \cdot 3$ & $6 \cdot 7$ & $7 \cdot 5$ & $4 \cdot 2$ & $1 \cdot 6$ & $32 \cdot 7$ & $92 \cdot 4$ & $6 \cdot 7$ & $\cdot 8$ \\
\hline
\end{tabular}

dyspnœa. It is interesting to see that over 25 per cent. of the children with a patent ductus arteriosus fall into this category, especially when this is compared with the percentage of 6.7 per cent. for the whole series. It is likely that some of these restrictions were imposed unnecessarily, as I have learnt that one child so advised on account of cardiac enlargement, won several races in the school sports last summer with no ill effects. The only child excused school attendance altogether was deeply cyanosed and dyspnœic, with marked clubbing of the fingers, and capable of very little exertion without distress.

Conclusions.-Definite symptoms are rare in these cases and disability to any appreciable extent occurs in less than 8 per cent. The best index of disability lies in a consideration of symptoms and not in the interpretation of the physical signs. 


\section{Radiographic investigation.}

Radiograms of the chest were taken at a distance of 6 feet at the end of normal inspiration. These have been measured and the 'cardio-thoracic ratio' calculated according to the method of Martin ${ }^{2}$. Any peculiarity in the shape of the cardiac shadow found fell very closely into the groups described by Lincoln and Spillman ${ }^{3}$ in their investigations of normal children. The distribution of these types was much the same as found by these workers, and there was no marked incidence of any particular shape of heart in any group or in the series as a whole. Occasionally changes in the shape of the heart were noted with increase of age, as was also found in the normal children.

The salient radiographic findings are shown in Table 2.

TABLE 2 .

Main radological findings, in percestages.

\begin{tabular}{|c|c|c|c|c|c|c|c|c|}
\hline \multirow{3}{*}{ Group } & \multirow{3}{*}{$\begin{array}{c}\text { Total } \\
\text { number }\end{array}$} & \multicolumn{4}{|c|}{ Cardio-thoracic ratio } & \multicolumn{3}{|c|}{ Peculiarities of shape } \\
\hline & & \multirow[b]{2}{*}{$\begin{array}{c}\text { Below } \\
45\end{array}$} & \multirow[b]{2}{*}{$45-50$} & \multirow[b]{2}{*}{$50-5 \overline{5}$} & \multirow[b]{2}{*}{$\begin{array}{c}\text { Over } \\
\overline{5} \overline{5}\end{array}$} & \multicolumn{2}{|c|}{ Pulmonary conus } & \multirow{2}{*}{$\begin{array}{c}\text { Prominent } \\
\text { left } \\
\text { ventricle }\end{array}$} \\
\hline & & & & & & Prominent & $\begin{array}{c}\text { Very } \\
\text { prominent }\end{array}$ & \\
\hline 1 & 37 & $10 \cdot 8$ & $56 \cdot 7$ & $32 \cdot 4$ & 一 & $16 \cdot 2$ & - & - \\
\hline 2 & $\tilde{5}$ & $40 \cdot 0$ & $40 \cdot 0$ & $20 \cdot 0$ & - & $20 \cdot 0$ & - & 一 \\
\hline 3 & 39 & $7 \cdot 6$ & $58 \cdot 0$ & $15 \cdot 3$ & $17 \cdot 6$ & $46 \cdot 1$ & $7 \cdot 6$ & - \\
\hline 4 & 26 & $15 \cdot 3$ & $42 \cdot 3$ & $30 \cdot 7$ & $11 \cdot 3$ & $7 \cdot 6$ & $7 \cdot 6$ & 一 \\
\hline 5 & 7 & - & $42 \cdot 8$ & $28 \cdot \pi$ & $28 \cdot 5$ & $71 \cdot 3$ & - & - \\
\hline 6 & 5 & - & $60 \cdot 0$ & - & $40 \cdot 0$ & - & 一 & $40 \cdot 0$ \\
\hline Total & 119 & $10 \cdot 9$ & $52 \cdot 9$ & $24 \cdot 3$ & $11 \cdot 7$ & $26 \cdot 8$ & $4 \cdot 2$ & $1 \cdot 6$ \\
\hline
\end{tabular}

Discussion.-Prominence of the pulmonary conus is not by any means diagnostic of an anomaly of the heart, since Lincoln and Spillman ${ }^{3}$ found it in $21 \cdot 3$ per cent. of their normal children, and the incidence in this series $(26 \cdot 8$ per cent.) is little higher than that. The cases classed as showing a very prominent pulmonary conus present much more accentuation of this curve in the radiograms than the most marked case found by the above mentioned authors in normal children. It is probable, therefore, that such an extreme prominence of this portion of the cardiac shadow as shown in Fig. 1 is always indicative of an organic disease of the heart. That this lesion is not necessarily congenital in origin is shown by the case reported by Schwartz and Shelling ${ }^{4}$ 
in which a rheumatic process produced an even more extreme dilatation of the pulmonary artery. . The X-ray examinations confirm the comparatively slight significance of the lesions in Groups 1 and 2 deduced from the clinical findings, since none of these cases shows any severe degree of cardiac enlargement. No gross enlargement of the right side of the heart was found in any case but the radiograms revealed enlargement of the left ventricle, clinically unsuspected, in two of the cases of sub-aortic stenosis, thus confirming this interpretation

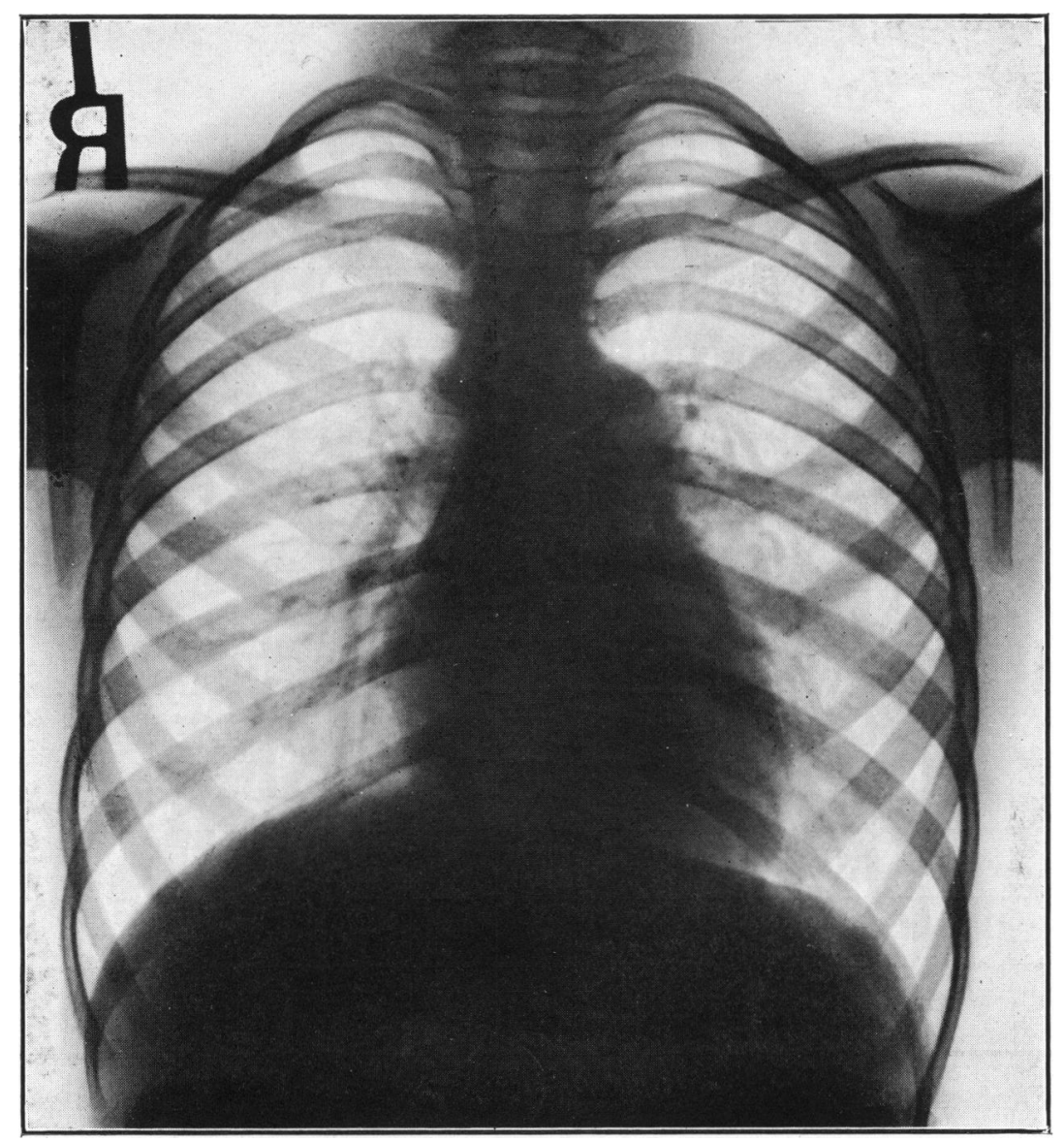

FIt. 1. Skiagram of a case in Group 3, showing marked prominence of the pulmonary conus.

of the physical signs. Apart from this the radiographic investigation failed to throw much light either on the underlying anatomical defect or on the differential diagnosis between these and acquired lesions of the heart.

Conclusions.-Although a radiogram of the chest may reveal more (or less) cardiac enlargement than is expected clinically, it is not of great help in the diagnosis of the conditions under consideration. 


\section{Electrocardiographic investigation.}

Electrocardiograms were taken with the patient sitting, using nonpolarizable immersion electrodes and a standard Cambridge galvanometer. These tracings have been examined with special reference to the P-R interval, amplitude of the Q.R.S. complex, and the duration of the S-T interval. Further, the electrical axis of the heart has been calculated by the method described by Carter, Richter and Greene ${ }^{5}$. Table 3 shows the electrocardiographic features so obtained.

TABLE 3.

INCIDENCE OF THE MAIN ELECTROCARDIOGRAPHIC FINDINGS, IN PERCENTAGES.

\begin{tabular}{|c|c|c|c|c|c|c|c|c|c|c|c|c|c|c|c|c|}
\hline \multirow[b]{2}{*}{ 号 } & \multirow[b]{2}{*}{ 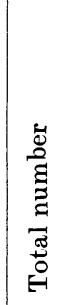 } & \multirow[b]{2}{*}{ 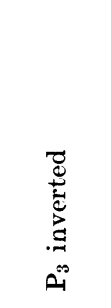 } & \multicolumn{3}{|c|}{ P-R interval } & \multicolumn{3}{|c|}{ Q.R.S. } & \multicolumn{3}{|c|}{ S-T interval } & \multicolumn{2}{|c|}{$\mathrm{T}$} & \multicolumn{3}{|c|}{ Electrical axis } \\
\hline & & & 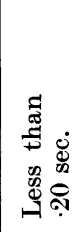 & 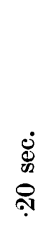 & 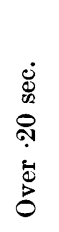 & 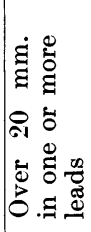 & 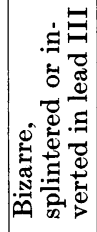 & 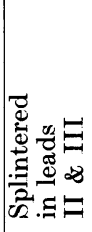 & 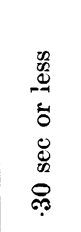 & 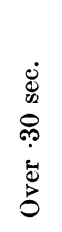 & 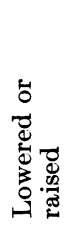 & 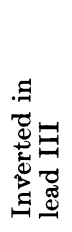 & 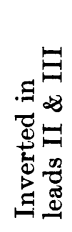 & 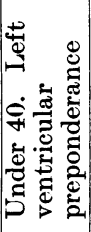 & 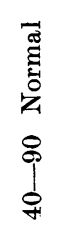 & 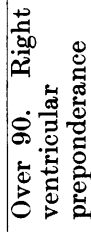 \\
\hline 1 & 37 & $5 \cdot 4$ & 94.5 & $5 \cdot 4$ & -- & $15 \cdot 6$ & $21 \cdot 6$ & - & $91 \cdot 8$ & $8 \cdot 1$ & - & $54 \cdot 0$ & - & $21 \cdot 6$ & $78 \cdot 3$ & - \\
\hline 2 & 5 & $\begin{array}{c}20 \cdot 0 \\
(\mathrm{P} 2 \& 3)\end{array}$ & $100 \cdot 0$ & - & - & - & - & $20 \cdot 0$ & 100.0 & - & - & $60 \cdot 0$ & - & $40 \cdot 0$ & $40 \cdot 0$ & $20 \cdot 0$ \\
\hline 3 & 39 & $2 \cdot 5$ & $89 \cdot 7$ & $5 \cdot 1$ & $5 \cdot 1$ & $20 \cdot 5$ & $16 \cdot 3$ & $2 \cdot 5$ & $92 \cdot 3$ & $7 \cdot 6$ & $5 \cdot 1$ & $38 \cdot 4$ & $5 \cdot 1$ & $12 \cdot 8$ & $46 \cdot 1$ & $41 \cdot 0$ \\
\hline 4 & 26 & $3 \cdot 8$ & $100 \cdot 0$ & 一 & - & $15 \cdot 3$ & $19 \cdot 2$ & - & $92 \cdot 3$ & $7 \cdot 6$ & - & $80 \cdot 7$ & - & $23 \cdot 0$ & $65 \cdot 3$ & $11 \cdot 5$ \\
\hline 5 & 7 & 一 & $100 \cdot 0$ & - & - & $42 \cdot 8$ & $14 \cdot 2$ & - & $100 \cdot 0$ & - & - & $14 \cdot 2$ & - & $42 \cdot 8$ & $57 \cdot 1$ & - \\
\hline 6 & 5 & - & $100 \cdot 0$ & - & - & - & $20 \cdot 0$ & - & $100 \cdot 0$ & - & - & $80 \cdot 0$ & - & $40 \cdot 0$ & $60 \cdot 0$ & - \\
\hline Total & 119 & $4 \cdot 2$ & $94 \cdot 9$ & $3 \cdot 3$ & $1 \cdot 6$ & $16 \cdot 8$ & $17 \cdot 4$ & $1 \cdot 6$ & $93 \cdot 2$ & $6 \cdot 7$ & $1 \cdot 6$ & $53 \cdot 7$ & $1 \cdot 6$ & $21 \cdot 9$ & $61 \cdot 3$ & $16 \cdot 8$ \\
\hline
\end{tabular}

Discussion.-The inversion of the $P$ wave in lead III in a few cases is of no significance as it was found in 8 per cent. of our series of normal children (6). Prolongation of the P-R interval was confined to Groups 1 and 3 , in both of which it is supposed from a consideration of the physical signs that there is present a patency of the inter-ventricular septum. The finding of a partial heart block supports this view and suggests that in these cases the auriculoventricular bundle has been involved in the septal deficiency. No case of complete block was found. The increased amplitude of the Q.R.S. deflection found in 16.8 per cent. of all these cases is interesting, and it would appear that such a finding, in the absence of any marked preponderance of one or other ventricle, is suggestive of a congenital defect. Seham ${ }^{7}$ made a similar observation in 2 of the 16 cases which he reports $(12.5$ per cent.). Seham also found 
that splintering of Q.R.S. occurred frequently in congenital abnormalities of the heart, but the significance of this change in lead III would appear doubtful since we have found it in 21 per cent. of our normal ehildren ${ }^{6}$. However, in 1.6 per cent. of this series it was associated with a splintering of this complex in lead II also, and this association may have some significance since it was found in none of the normal children. Seham in the paper already mentioned suggests that a prolongation of the $\mathrm{S}-\mathrm{T}$ interval is characteristic of congenital heart disease. In this study $0 \cdot 30$ seconds has been regarded as the highest
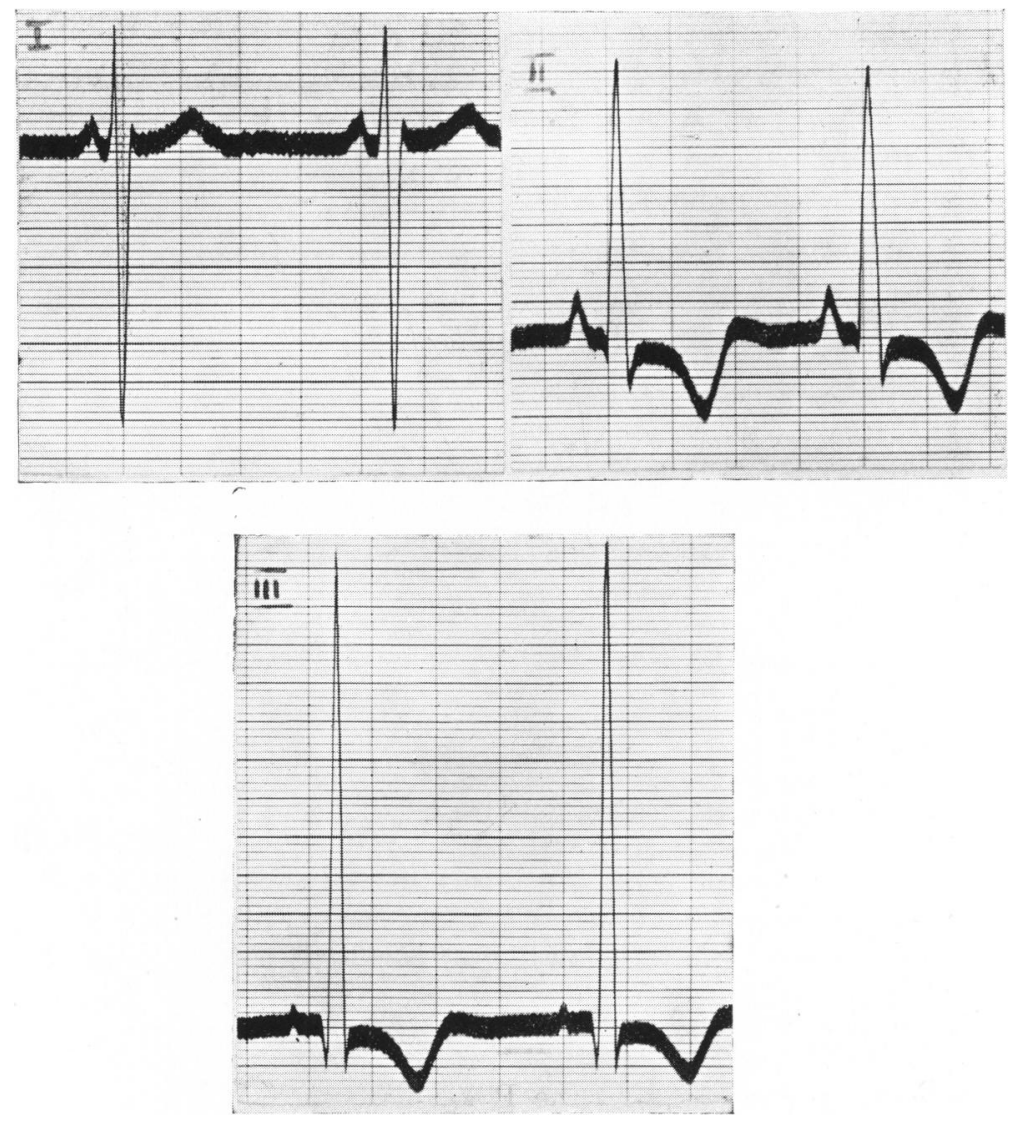

Fig. 2. Electrocardiogram of a case in (iroup 3.

normal duration of this phase and it is seen that only $6 \cdot 7$ per cent. of the cases exceed this figure. Thus the present investigation lends little support to Seham's conclusion. In two cases in Group III the S-T interval was raised in lead I and lowered in leads II and III, and this was associated with a large amplitude of Q.R.S. in all leads and inversion of $\mathrm{T}$ in leads II and III. The tracing thus produced (Fig. 2) is almost identical with one figured by Abbott ${ }^{8}$ from a case of pulmonary stenosis with defect of the interventricular septum and dextro-position of the aorta. These tracings are very reminiscent of some 
seen following occlusion of one of the main branches of a coronary artery. The frequency with which $\mathrm{T}$ was inverted in lead III (.53 per cent.) is almost identical with that found in normal children ( 54 per cent.) although rather more than that found by Lincoln and Nicholson ${ }^{9}(35 \cdot 5$ per cent.)

The incidence of right ventricular preponderance is strikingly low-only 16.8 per cent. of the whole series. But of these 80 per cent. occurred in Group 3, thus confirming the conclusion to be drawn from the clinical and radiological investigation that it is in this group that the right side of the heart is most affected by the congenital malformation. However, none of these changes occur with sufficient frequency, either in the whole series or in any individual group, for them to afford much assistance in the diagnosis of these conditions. Where marked right ventricular preponderance or gross abnormalities were found, the patient was generally cyanosed or dyspnœic, and the diagnosis quite clear on clinical grounds alone.

Conclusion.--There is no characteristic electrocardiogram of congenital heart disease, and electrocardiography has proved of little value in the diagnosis and differentiation of these minor congenital abnormalities of the heart.

In conclusion my thanks are due to Dr. Carey Coombs for his help and advice; to Dr. F. G. Bergin and Dr. G. B. Bush, radiologists to the Bristol General Hospital, for the radiograms ; and to Mr. C. Prout and Mr. H. Wakefield for their technical assistance.

\section{REFERENCES.}

1. Vaquez, H., Dis. of the Heart, London, 1924, 180.

2. Martin, C. L., Am. J. Roentgen, 1921, VIII, 295.

3. Lincoln, E. M., \& Spillman, R., Am. J. Dis. Chill., Chicago, 1928, XXXV, 791.

4. Schwartz, S. P., \& Shelling, D., Am. Heart J., 1931, IV, 568.

5. Carter, E. P., Richter, C. P., \& Greene, C. H., Bull. John's Hoplins Hosp., Baltimore, 1919, XXX, 162.

6. Perry, C. B., Arch. Dis. Childh., London, 1!31, V I, 259.

7. Seham, M., Abt's Pediatrics, 1924, IV.

8. Abbott, M. E., Modern Medicine, London, 1927, IV, 740.

9. Iincoln, E. M., \& Nicholson, G. H. B., Am. J. Dis. Child., Chicago, 1928, XXXV, 1001. 